Universidade Tecnológica Federal do Paraná - UTFPR

Campus Ponta Grossa - Paraná - Brasil

ISSN: 1981-3686/ v. 08, n. 02: p. 1360-1373, 2014

D.O.I. $10.3895 / \mathrm{S} 1981-36862014000200006$

\author{
Revista Brasileira de Tecnologia \\ Agroindustrial
}

\title{
CONCEPÇÃO E ANÁLISE ECONÔMICA DE UMA ESTAÇÃO DE EMBALAGEM DE MAÇÃS IN NATURA
}

\section{DESIGN AND ECONOMIC ANALYSIS OF AN APPLE PACKING HOUSE}

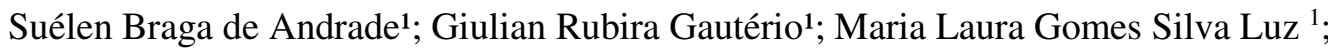 \\ Carlos Alberto Silveira Luz ${ }^{1}$; Gizele Ingrid Gadotti ${ }^{1}$; Mário Conill Gomes ${ }^{1}$ \\ ${ }^{1}$ Universidade Federal de Pelotas- Pelotas- RS- Brasil suelenb.andrade@gmail.com
}

\begin{abstract}
Resumo
O estudo de caso refere-se a uma propriedade rural com 35 ha de pomares, sendo $50 \%$ da área plantada com macieiras do grupo Gala e 50\% Fuji. O objetivo do presente trabalho foi estudar a viabilidade técnico-econômica da instalação de uma estação de beneficiamento e embalagem de maçã "in natura", prevendo uma ampliação, a partir do quarto ano, totalizando 3.000 t.ano-1. Para o dimensionamento dos equipamentos foi calculado o balanço de massa. Além disso, foi realizado o planejamento do número de funcionários necessários e de suas funções. Para análise de mercado foi realizada uma pesquisa de opinião, por meios digitais, para pessoas de diferentes cidades do Rio Grande do Sul, de diferentes idades, classes sociais e escolaridade. Quanto ao estudo econômico, realizou-se uma análise estratégica para a determinação da unidade de negócio. Os investimentos foram planejados para ser realizados no ano zero e três do horizonte de planejamento de 10 anos. Uma vez obtidos todos os valores, elaborou-se o fluxo de caixa. Foram construídos cenários econômicos para simular diferentes situações baseadas em acontecimentos de risco, para qualquer produção agrícola, neste caso, os fatores climáticos. Conclui-se que em qualquer cenário econômico estudado o projeto é viável e atrativo, até na pior condição climática, pois ainda tem-se um payback pequeno (4 anos) e um alto valor da VPL. A TIR em todos os cenários é maior que a TMA, indicando que mais vale investir no projeto, a deixar o dinheiro em alguma aplicação financeira.
\end{abstract}

Palavras-chave: Malus domestica; packing house; processamento agroindustrial.

\section{Introdução}

O maior produtor mundial de maçãs é a China, produzindo cerca de $33 \mathrm{Mt}$ ao ano (FAO, 2010). O Brasil ocupa a 9a posição no ranking mundial de países produtores de maçãs, com 1,279 Mt.

A cultura da maçã no Brasil iniciou com a chegada dos primeiros colonizadores europeus. Em 1962, em Fraiburgo (SC) foi implantado um grande pomar comercial, incluindo uva, maçã e frutas de caroço. Porém, o grande salto da produção de maçãs no país aconteceu a partir da metade da década de 70 quando o Governo Federal incluiu a macieira na Lei de Incentivos Fiscais para 
Reflorestamento, que permitiu o surgimento dos primeiros pomares comerciais na região de Fraiburgo e, nos anos seguintes, no Paraná e no Rio Grande do Sul (ABREU et al., 2009).

A partir de 1988, o Brasil passou a exportar maçãs, atingindo a autossuficiência em 1998, quando as exportações ultrapassaram as importações (PETRI; LEITE, 2008).

O Rio Grande do Sul é o segundo maior estado produtor de maçãs do Brasil, atrás apenas de Santa Catarina. Na safra de 2012, o estado produziu 620.891 t, enquanto a produção do país é estimada em 1.338.270 t (IBGE, 2012). A principal região produtora é a nordeste do estado, sendo Vacaria o principal produtor, com 253.394 t na safra 2011/2012, seguido por Caxias do Sul com 56.763 t e Bom Jesus com 50.597 t (AGAPOMI; EMATER, 2012).

A macieira, Malus domestica, é uma planta da família das rosáceas, perene, de porte arbóreo, com uma vida média de 20 anos. Possui algumas peculiaridades quanto à exigência de frio para superação de dormência, solos com boa profundidade e fertilidade e capacidade de drenagem. Essas condições ocorrem na região nordeste do estado do Rio Grande do Sul, especialmente nas maiores altitudes, que permitem o plantio de cultivares de médio a alto requerimento em horas de frio, como Gala e Fuji. As frutas adquirem boa coloração, suculência, crocância e bom equilíbrio entre açúcares e acidez. Além disso, a região possui disponibilidade de terras para novos investimentos e a estrutura produtiva instalada, que inclui fornecedores de mudas, insumos, máquinas e equipamentos para produção e colheita, armazéns de beneficiamento e câmaras de armazenamento refrigerado (EPAGRI, 2002; FIORAVANÇO et al., 2010).

A maçã, por ser um produto perecível, requer tecnologia adequada e eficiência operacional no manejo pós-colheita, para garantir a qualidade e o abastecimento contínuo da fruta ao longo do ano. A maior parte da produção de maçã é destinada ao armazenamento em câmaras frias, com temperatura de $0^{\circ} \mathrm{C}$ para a Gala e de -1 a $1^{\circ} \mathrm{C}$ para a Fuji e umidade relativa do ar de 94 a $96 \%$ para a Gala e de 92 a 96\% para a Fuji. Nestas condições, o período de armazenamento é de 4-5 meses para a Gala e de 6-7 meses para a Fuji. Para ter um armazenamento satisfatório, é preciso ser efetuada uma colheita no momento certo e com frutos de qualidade (EPAGRI, 2002; GIRARDI et al., 2004).

Sua classificação ocorre em modernos sistemas, programados eletronicamente para separar as frutas de acordo com sua cor e calibre dentre outros aspectos, conforme Pereira et al. (2007). O local onde as maçãs ficam armazenadas e de onde saem classificadas e embaladas é chamado de packing house.

A estação ou unidade de embalagem (packing house) deve ser localizada próxima à área de produção para que o transporte dos produtos seja reduzido ao mínimo, com bom acesso aos veículos de transporte, suprimento adequado de água, eletricidade e boa drenagem (CHITARRA; CHITARRA, 2005). 
O controle da contaminação por Penicilium expansum nas packing houses é obtido realizando os procedimentos corretos de higienização e desinfecção, como forma de evitar a formação da patulina. A patulina é uma micotoxina termo-resistente, ocasionada pelo gênero Penicilium e por várias espécies de fungos, comuns em vegetais, produtos derivados e principalmente em maçãs. Porém, há preocupação com a ocorrência da patulina também em sucos e derivados de maçãs, pois estudos sobre a toxicidade em animais demonstraram que esta micotoxina possui caráter teratogênico, cancerígeno e imunotóxico em camundongos (CELLI et al, 2009).

Para se conhecer a viabilidade da implantação de uma packing house é importante associar o projeto de engenharia à análise econômica. As decisões sobre a viabilidade econômica de projetos resultam da estimativa e análise de indicadores de viabilidade. Dentre esses indicadores podem-se destacar o Valor Presente Líquido (VPL), correspondendo à soma algébrica dos valores do fluxo de caixas futuros, atualizados à taxa ou às taxas de desconto do período, segundo esse indicador, a atividade é viável se apresentar VPL positivo (BUARQUE, 1996; PERES et al., 2009).

A Taxa Interna de Retorno (TIR), definida por Contador (1988) é a taxa de desconto que iguala o VPL dos benefícios ao valor presente dos custos de um sistema de produção, ou seja, iguala a zero. Um sistema é viável quando sua TIR é igual ou maior que o custo de oportunidade do capital (Taxa Mínima de Atratividade - TMA). Outro indicador é a Taxa Interna de Retorno Modificada (TIRm) que permite fixar taxas de reinvestimento mais realistas que a TIR para os fluxos de caixa, levando a um cálculo mais correto do rendimento anual do projeto. O período de retorno do capital investido (payback) é também um indicador importante a ser determinado. Deve-se salientar que a análise desses indicadores deve ser feita de maneira conjunta para auxiliar na tomada de decisão, segundo Bruni et al. (1998), Figueiredo et al. (2006) e Sampaio Filho (2008).

Corroborando, Peres et al. (2004) citam que um projeto é viável e deve ser adotado quando sua TIR é igual ou maior que o custo de oportunidade dos recursos para sua implantação.

O estudo de caso refere-se a uma propriedade rural que já possui 35 ha de pomares implantados e em plena produção, sendo $50 \%$ da área plantada com macieiras de cultivares do grupo Gala e 50\% com macieiras de cultivares do grupo Fuji.

Atualmente, a produção da propriedade é entregue a terceiros para beneficiar e embalar, e a fruta desclassificada, um subproduto (maçã tipo industrial) fica com esses para ser vendida para indústrias processadoras de sucos e sidras, não dando retorno financeiro ao produtor, além do custo com o frete até a empresa terceirizada. O produtor recebe apenas pela fruta classificada, segundo a Instrução Normativa no 05 de 09/02/2006 da Lei no 9972 do MAPA, deixando de receber pela maçã tipo industrial.

O objetivo do presente trabalho foi estudar a viabilidade técnico-econômica da instalação de uma estação de beneficiamento e embalagem de maçã "in natura” (packing house), no município de 
Bom Jesus-RS, prevendo uma ampliação, devido ao plantio de novo pomar, a partir do quarto ano, totalizando 3.000 t.ano ${ }^{-1}$ de frutas.

\section{Material e métodos}

O pomar em estudo está localizado no município de Bom Jesus, RS, com uma produção média de 2.100 t.ano ${ }^{-1}$ de frutas. Porém, o produtor pretende ampliar seu pomar em uma área de mais 15 ha que resultará em um aumento de 900 t.ano $^{-1}$ de maçãs a serem processadas, a partir do quarto ano de funcionamento da estação de beneficiamento. O local de implantação foi estabelecido próximo ao pomar.

Para o dimensionamento dos equipamentos foi calculado o balanço de massa, utilizando os dados de produtividade média fornecidos pelo produtor, com um conceito de processamento durante todo o ano. Por esta razão, também se realizou o dimensionamento de câmaras frigoríficas para o armazenamento refrigerado de maçãs. Além disso, foi realizado o planejamento do número de funcionários necessários e de suas funções, salários e encargos financeiros.

Para a elaboração da planta baixa e cortes que definiram o layout dos equipamentos e distribuição no interior da estação de beneficiamento de maçãs, utilizou-se um software de desenho.

Para análise de mercado foi realizada uma pesquisa de opinião, por meios digitais, para pessoas de diferentes cidades do Rio Grande do Sul, de distintas idades, classes sociais e escolaridade, com o intuito de estimar e conhecer as preferências e a qualidade da maçã em diversas regiões do estado.

Quanto ao estudo econômico, inicialmente, realizou-se uma análise estratégica e de mercado para a determinação da unidade estratégica de negócio pelo modelo da matriz de Ansoff, como descrito por Monteiro Neto (2001). Após, definiram-se o preço e as projeções de venda. Os preços de venda foram estimados com base em uma série história de 5 anos de preços médios mensais pagos no CEASA de Porto Alegre (CONAB, 2012), e os preços foram ajustados pelo índice IGPDI, com base no mês de dezembro de 2012.

Posteriormente, de posse do projeto técnico, foram determinados os valores dos investimentos fixos, bem como todos os demais gastos necessários para a execução do projeto. Os investimentos foram planejados para ser realizados no ano zero do horizonte de planejamento de 10 anos e também no ano três, quando ocorrerá a ampliação da estação de beneficiamento de maçãs. Uma vez obtidos todos os valores, elaborou-se o fluxo de caixa.

Foram construídos cenários econômicos para simular diferentes situações baseadas em acontecimentos de risco, para qualquer produção agrícola, neste caso, os fatores climáticos. 
Em um cenário pessimista, estimou-se uma quebra na safra de maçãs de $20 \%$, ocasionados geralmente por queda de granizos na época de frutificação e geadas na fase de floração, como o que ocorreu na safra deste ano em alguns locais.

Em um cenário otimista, todos os fatores climáticos e de solo são favorecidos e tem-se um acréscimo de $20 \%$ na quantidade produzida.

Todos os gastos, fluxo de caixa e indicadores econômicos foram confeccionados com auxílio de uma planilha eletrônica.

Os indicadores econômico-financeiros utilizados foram: VPL, TIR, TIRm, payback, segundo Buarque (1991) e Bruni et al. (1998) e a TMA (Taxa Mínima de Atratividade) considerada foi de $12 \%$.

A equação para cálculo do VPL é a seguinte:

$V P L=\sum_{t=0}^{n} \frac{V F}{(1+r)^{t}}$

Equação 1

onde: $\mathrm{VF}=$ valor do fluxo líquido (diferença entre entradas e saídas); $\mathrm{n}=$ número de fluxos; $\mathrm{r}=$ taxa de desconto; $\mathrm{t}=$ período de análise $(\mathrm{i}=1,2,3 \ldots)$.

A equação para cálculo da TIR é a seguinte, sendo a TIR o valor em que r se iguala a zero:

$V P L=V F_{0}+\frac{V F_{1}}{(1+r)^{1}}+\frac{V F_{2}}{(1+r)^{2}}+\cdots+\frac{V F_{n}}{(1+r)^{n}}$

onde: $\mathrm{VF}=$ fluxos de caixa líquido $(0,1,2,3, \ldots, \mathrm{n}) ; \mathrm{r}=$ taxa de desconto.

\section{Resultados e discussões}

Com base no levantamento da produtividade do pomar atual e sua ampliação foi estabelecido que a agroindústria iniciará sua produção com 8,67 t.dia ${ }^{-1}$, sendo ampliada no quarto ano de funcionamento para 12,4 t.dia $^{-1}$ de maçãs. Com este dado foi dimensionado o fluxograma e o balanço de massa (Figura 1), incluindo a maçã a ser beneficiada e embalada após a ampliação.

A partir disso, foi conceituado o processo pelas seguintes premissas: quando do início da colheita das maçãs do cultivar Gala estimou-se um recebimento médio de 34,09 t.d $\mathrm{d}^{-1}$. Estas serão recebidas em caixas de madeira de $300 \mathrm{~kg}$ (bin), pesadas e inspecionadas quanto à qualidade (firmeza da polpa, sólidos solúveis e defeitos). Em seguida, parte das frutas recebidas $\left(21,69\right.$ t.d $^{-1}$ ) será armazenada e o restante $\left(12,4\right.$ t. $\left.\mathrm{d}^{-1}\right)$ será encaminhado para a limpeza. Ao término da colheita, que compreenderá o período da segunda quinzena de janeiro até a segunda quinzena de março, 
totalizando cerca de dois meses, toda a fruta do cultivar Gala a ser processada será proveniente das câmaras frigoríficas de armazenamento.

Figura 1 - Fluxograma e balanço de massa diário da packing house em estudo.

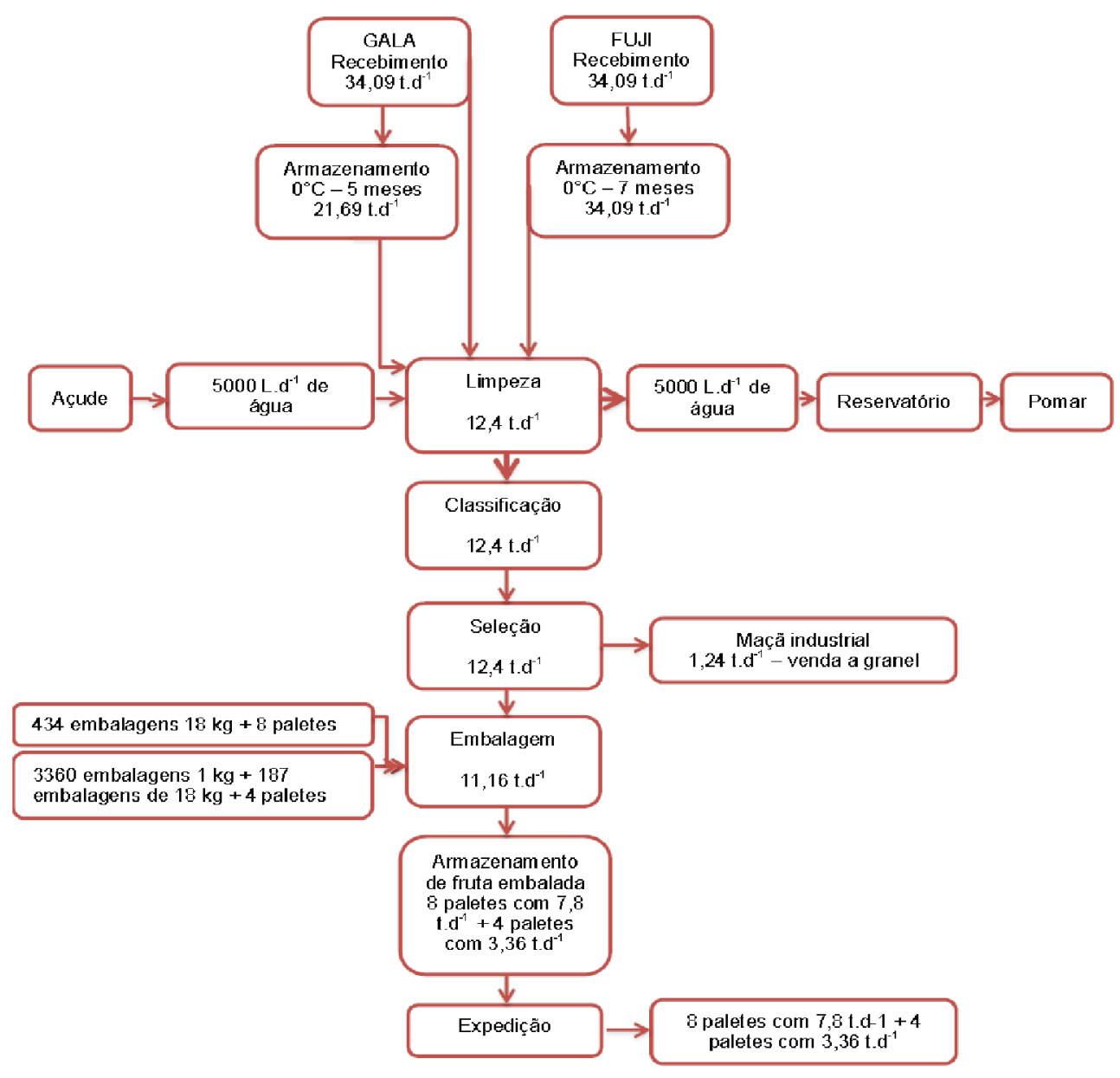

Com isso, o dimensionamento das câmaras frias foi estabelecido de acordo com a colheita e o processamento das maçãs (Tabela 1). Posteriormente, terá início a colheita das maçãs do cultivar Fuji, porém toda a quantidade colhida por dia, que será a mesma do cultivar Gala, será armazenada, devido à maior resistência ao armazenamento. Por isso, escolheu-se processar toda a maçã Gala primeiro e só depois o cultivar Fuji, fazendo com que se tenha maçã para ser processada o ano inteiro.

Antes das frutas serem armazenadas na câmara será realizada a higienização (lavagem) das paredes e piso desta e após uma pulverização com digluconato de clorohexidina, para evitar a incidência de podridões nas frutas armazenadas, causadas por Penicilium expansum, conforme recomendação de Sanhueza (1996), evitando também a formação de patulina. 
Tabela 1 - Quantidades de maçãs armazenada em câmaras frias e processada durante os meses do ano (em no de bins) para uma produção de 34,09 t.dia ${ }^{-1}$

\begin{tabular}{cccc}
\hline Mês & $\begin{array}{c}\text { Quant. armazenada } \\
\left(\mathbf{n}^{\mathbf{0}} \text { de } \text { bins }\right)\end{array}$ & $\begin{array}{c}\text { Quant. processada } \\
\left(\mathbf{n}^{\mathbf{0}} \text { de } \text { bins }\right)\end{array}$ & $\begin{array}{c}\text { Total } \\
\left(\mathbf{n}^{\mathbf{0}} \text { de } \text { bins }\right)\end{array}$ \\
\hline jan-fev & 1113 & & 1113 \\
fev-mar & 1113 & & 2226 \\
mar-abr & 1750 & 636 & 3340 \\
abr-mai & 1750 & 636 & 4454 \\
mai-jun & & 636 & 3818 \\
jun-jul & & 636 & 3182 \\
jul-ago & 636 & 2546 \\
ago-set & & 636 & 1910 \\
set-out & 636 & 1274 \\
out-nov & 636 & 638 \\
nov-dez & & 636 & 2 \\
dez-jan & & Férias coletivas & \\
\hline
\end{tabular}

A limpeza das frutas será realizada por imersão em tanques contendo água proveniente do açude da propriedade e que será previamente clorada. $\mathrm{O}$ operador de empilhadeira irá retirar uma caixa de madeira do recebimento, ou do armazenamento e irá depositar no interior do lavador (tanque). As maçãs ficarão imersas por cerca de 2 a 3 min, em temperatura ambiente. A capacidade para este tanque será de $5.000 \mathrm{~L}$ de água. Ao final do dia esta água será retirada do tanque e transportada, por meio de tubulações até um reservatório, onde ficará armazenada para ser utilizada posteriormente, para a irrigação dos pomares.

Após a lavagem das frutas (Figura 2a), estas deverão seguir por um elevador de roletes, até a escovação/polimento e secagem (Figura $2 b$ e $2 c$ ). A escovação/polimento se dará por conjuntos de escovas de nylon rotativas. A secagem será realizada por ventiladores instalados sobre o conjunto de escovas, ou seja, as duas etapas ocorrerão ao mesmo tempo.

As maçãs serão classificadas por peso, por um classificador de copos mecânico, com capacidade para processar até $4 \mathrm{t} \cdot \mathrm{h}^{-1}$, que realizará a pesagem, fruta a fruta, e a destinará à devida mesa de seleção, de acordo com o seu calibre (Figura 2d). Nas mesas de seleção (Figura 2e), ficarão oito funcionárias, com rígido controle de higiene, conforme as Boas Práticas Pós-colheita na Produção Integrada de Maçãs (GIRARDI, 2002), que selecionarão visualmente as maçãs de acordo com a qualidade das mesmas, que é dada pela cor, em categorias extra, 1, 2 e 3 e defeitos, conforme as normas do MAPA (2006). Neste ponto, também serão selecionadas as frutas de categoria industrial, que não serão embaladas, e sim vendidas a indústrias de suco e sidra da região. Estima-se que a maçã desta categoria seja $10 \%$ da quantidade total de fruta colhida por safra. 
Figura 2 - a) Tanque de imersão; b) Escovação; c) Ventiladores axiais protegidos com tela para secagem de maçãs; d) Calibrador de bandejas; e) Câmara manual de maçãs por cor

(a)

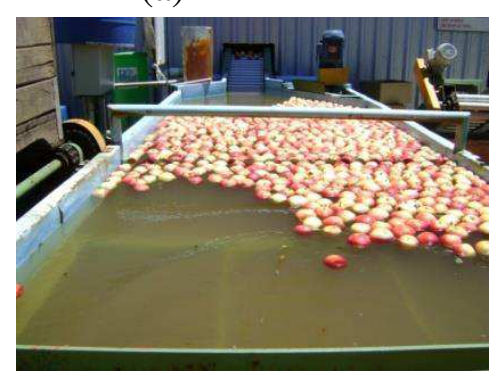

Fonte: Gautério, 2012 (b)

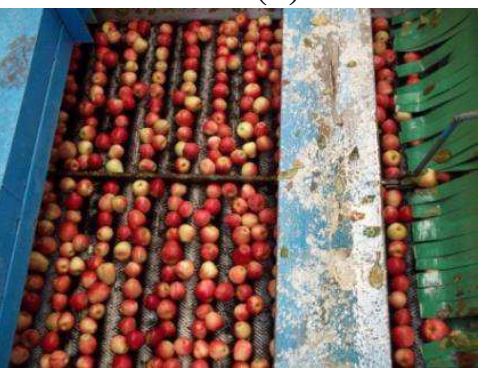

Fonte: Andrade, 2012 (d) (c)

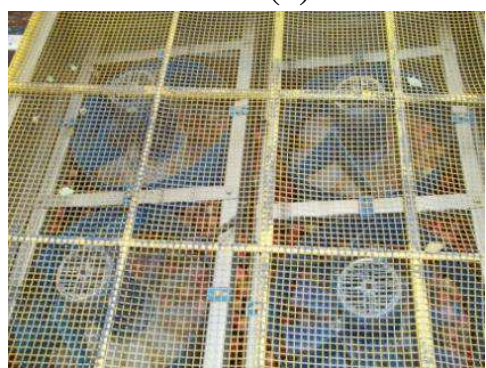

Fonte: Andrade, 2012

(e)

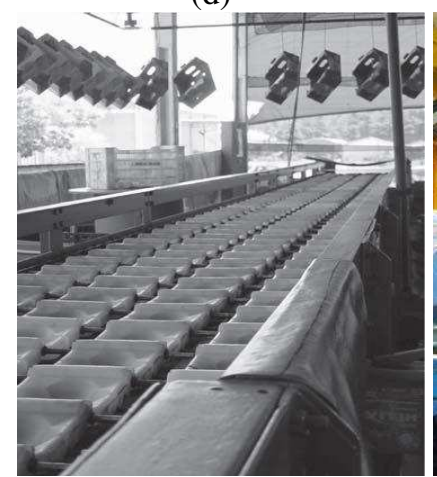

Fonte: Ferreira, 2008

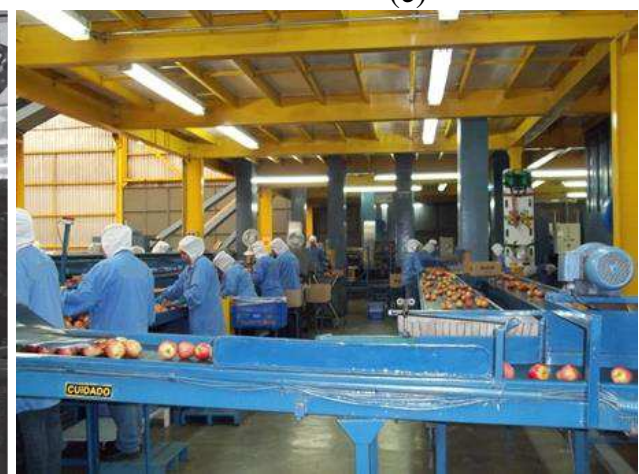

Fonte: Andrade, 2012

As maçãs que não se enquadram na categoria industrial, serão acondicionadas, pelas próprias selecionadoras, em bandejas, para que os dois embaladores, posteriormente as depositem nas caixas.

As embalagens serão compostas por caixas de papelão, com a capacidade de acondicionar $18 \mathrm{~kg}$ de maçãs, distribuídas em cinco bandejas, que serão sobrepostas, separadamente. Após, as caixas serão fechadas pelos embaladores e depositadas sobre um palete de madeira $(1,20$ x 1,00 m), totalizando 56 caixas por palete. Para a sustentação das caixas no palete, serão fixadas quatro cantoneiras de papelão e em seguida o palete será amarrado, manualmente, por dois funcionários (embaladores), com filme strecht e levado até a câmara frigorífica de armazenamento de fruta embalada, pelo operador de empilhadeira, onde aguardará até o momento da expedição.

Buscando a diversificação dos produtos de forma a acompanhar as tendências do mercado e de um consumidor cada vez mais exigente, a partir do quarto ano de funcionamento, a Unidade passará a embalar maçãs em sacolas individuais, de $1 \mathrm{~kg}$. Sendo assim, todo o excedente de maçã a ser embalada após a ampliação $\left(3,36\right.$ t.d $\left.\mathrm{d}^{-1}\right)$, será destinada a este tipo de embalagem.

Devido à ampliação, existirão duas linhas distintas de embalagens: uma de caixas de $18 \mathrm{~kg}$ e outra de sacolas de $1 \mathrm{~kg}$. A linha de maçãs em caixa não se alterará, ou seja, será realizada da mesma forma e com as mesmas quantidades de maçãs como descrito anteriormente. Para a realização da embalagem de $1 \mathrm{~kg}$, serão utilizadas $3,36 \mathrm{t}^{\mathrm{d}} \mathrm{d}^{-1}$ de maçãs e serão contratados mais quatro embaladores. Estes irão depositar as maçãs na sacola, pesá-la em uma balança digital e 
posteriormente selá-la em uma seladora térmica. Estas sacolas serão acondicionadas em caixas de papelão abertas (platô), com capacidade para 18 sacolas. Em seguida, as caixas serão paletizadas manualmente e os paletes levados, pelo operador de empilhadeira até a câmara frigorífica de expedição.

A expedição será realizada com a supervisão do técnico agrícola e do inspetor de qualidade. O operador de empilhadeira irá retirar os paletes do interior da câmara de armazenamento de fruta embalada e os depositará no caminhão. O transporte será por conta de cada cliente e se este optar por carregar as maçãs em caminhões abertos, não refrigerados, a empresa não irá se responsabilizar pela qualidade da fruta que chegará em seu estabelecimento.

Após toda essa conceituação do processo, foi planificado em planta baixa e em cortes a estação, com a distribuição dos equipamentos e as áreas destinadas às ampliações, conforme Figura 3.

Figura 3 - Planta baixa e cortes da estação de beneficiamento de maçãs para 34,09 t.dia-1
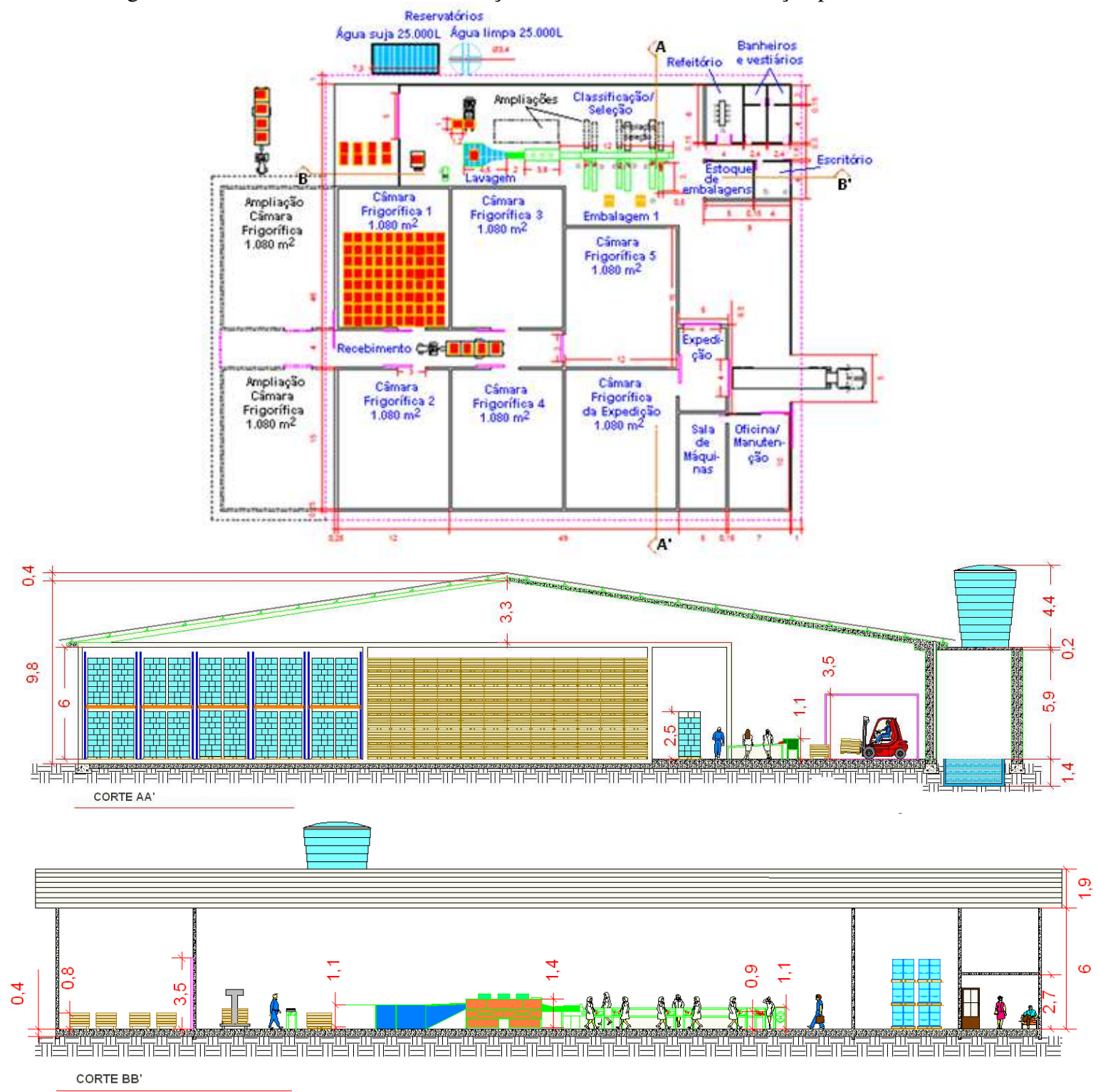
O número de funcionários foi calculado e seu total é de nove, trabalhando em jornada de 44 h semanais, com férias coletivas de 20 de dezembro a 20 de janeiro, quando não há colheita e toda a maçã armazenada já terá sido beneficiada e comercializada. As funções dos funcionários são: administrador, técnico agrícola, representante de vendas, secretária, inspetor de qualidade, embalador, selecionador e serviços gerais.

Com uma concepção prévia do processo, foi-se para a análise de mercado através das respostas de uma pesquisa de opinião. Responderam à pesquisa 210 pessoas, 91 do sexo masculino e 119 do sexo feminino, com idades de 20 a mais de 50 anos, com maior número de 110 participantes entre 21 e 30 anos, corroborando com os dados de Rombaldi et al. (2007) em um estudo de percepção de qualidade de frutas. A maioria (43\%) compra maçãs em supermercados e mercados regionais e/ou locais, seguidos por compras em fruteiras (27\%), 53\% se dizem satisfeitos com a qualidade das frutas que chegam até sua cidade. A maioria $(51 \%)$ prefere uma fruta com um menor número de defeitos, seguido por aqueles que preferem uma fruta com todos os atributos que continham na pesquisa (cor, tamanho, menor número de defeitos), que totalizaram $40 \%$ dos participantes. No entanto, Rombaldi et al. (2007) em sua pesquisa verificaram que a aparência geral das frutas, que inclui padronização, coloração, ausência de lesões e podridões, aspecto de produto "fresco", associado ao aroma (perfume) e ao sabor representou $12 \%$ do total das respostas dos participantes da pesquisa e o preço representou $18 \%$, sendo o item mais preponderante.

Estes resultados demonstram que o consumidor pesquisado está a cada dia mais interessado em produtos de melhor qualidade, o que é confirmado, quando lhes foi perguntado sobre o que levam em consideração no momento de compra das maçãs e $82 \%$ responderam que escolhem frutas pela sua maior qualidade e não pelo menor preço, dado esse que discorda de Rombaldi et al. (2007), que naquela data obteve $18 \%$ das respostas como preço sendo requisito de qualidade. Acredita-se que, devido ao público-alvo da pesquisa não ter uma limitação financeira para aquisição de maçãs, isto lhes proporciona a opção de qualidade superior. A Pesquisa de Orçamentos Familiares (POF), realizada pelo IBGE nos anos de 2008 e 2009 mostram o consumo per capita de maçãs e o perfil do consumidor, que diz que os maiores consumidores de maçãs são mulheres e possuem renda acima de R\$1.089,00.

Os participantes da pesquisa em sua maioria (45\%) preferem maçãs do cultivar Fuji e nacionais, contabilizando $83 \%$.

Assim sendo, a maçã beneficiada e embalada pela estação de beneficiamento em estudo deverá ser comercializada, através de contratos, para supermercados e mercados regionais e/ou locais e fruteiras, no estado do Rio Grande do Sul. Outra alternativa é a comercialização via centros de distribuição de frutas (Ceasa), onde existe a concentração de uma grande variedade de produtos em um mesmo local e diversificação de varejistas. 
Foram utilizadas duas estratégias competitivas: foco e diferenciação. O foco foi na qualidade do produto a ser oferecido ao consumidor, pelo rigoroso controle de qualidade. A partir do quarto ano no negócio, passará a ser utilizada a estratégia diversificação, com a inserção de uma embalagem diferenciada, individual $(1 \mathrm{~kg})$, de maçãs limpas e prontas para o consumo, porém com um custo mais elevado.

Os preços de venda foram estabelecidos mês a mês para ambas as variedades e ficaram entre $\mathrm{R} \$ 28,75$ em julho e $\mathrm{R} \$ 36,51$ em fevereiro para a Gala, ficando a Fuji com valores intermediários.

Para desenvolvimento da Unidade Estratégica de Negócio utilizou-se a matriz de Ansoff (Figura 4), a qual demonstra a penetração de mercado pretendida, o desenvolvimento do mercado e a diversificação, criando uma nova linha de embalagem.

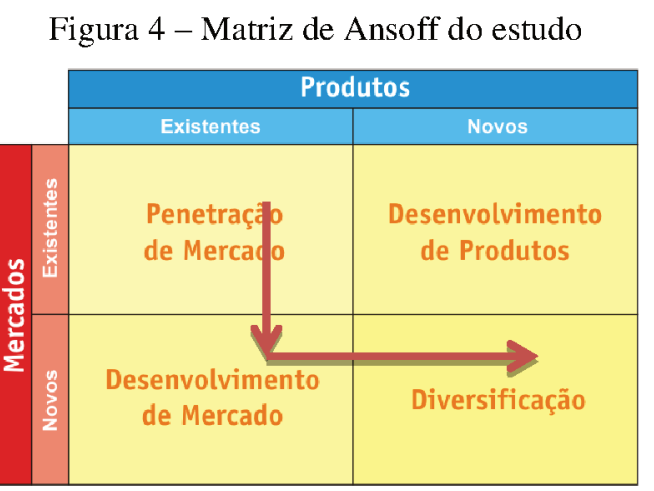

Fonte: Adaptado de Ansoff (1979, p.92).

Considerou-se um financiamento nos anos zero e três do horizonte de planejamento, de $50 \%$ do valor total de investimentos em ambos os casos e o restante, incluindo o capital de giro, será proveniente de recursos próprios. A linha de financiamento escolhida é Proger, do Banco do Brasil, com taxa de $8 \%$ a.a. e prazo para pagamento de 5 anos, sem carência, com sistema de amortização do tipo SAC, onde há amortização constante.

A Tabela 2 mostra os resultados da análise econômica para os cenários estudados.

Tabela 2 - Indicadores econômico-financeiros dos cenários estudados para a instalação da

\begin{tabular}{lccc}
\multicolumn{4}{c}{ estação de beneficiamento de maçãs de 34,09 t.dia $^{-1}$} \\
\hline Indicador & Normal & Pessimista & Otimista \\
\hline VPL (R\$) & $4.240 .125,55$ & $2.916 .025,72$ & $5.564 .225,38$ \\
TMA (\%) & 12 & 12 & 12 \\
TIR (\%) & 53,95 & 46,01 & 59,57 \\
TIRm (\%) & 30,75 & 29,22 & 31,69 \\
Payback (anos) & 3 & 4 & 2 \\
\hline
\end{tabular}

O Valor Presente Líquido para o projeto em estudo em todos os cenários apresentou valores positivos, que são favoráveis. Pode-se notar que ocorre uma redução no valor do VPL, quando 
comparado ao cenário do projeto em estudo (normal), mas mesmo assim este continua com um valor positivo.

Segundo Peres et al. (2004) o projeto é viável e deve ser adotado, pois a TIR em todos os cenários estudados foi maior que a TMA. A TIR modificada também ficou acima da TMA, mostrando se tratar de um projeto atrativo, conforme Sampaio Filho (2008), pois no cenário pessimista foi $29,22 \%$, bem acima da TMA de $12 \%$. Os valores de TIR e TIRm sendo maiores que a TMA, indicam que mesmo que haja alguma intempérie climática, com quebra de até $20 \%$ na produção de maçãs, o projeto ainda se mostra atrativo.

Para o cenário pessimista, pode-se perceber que o payback do projeto sobe para quatro anos e diminuem os valores de fluxo de caixa, quando diminui a quantidade produzida. O payback do projeto ocorre no terceiro ano do horizonte de planejamento no cenário normal e no segundo para o otimista, mostrando-se em todos os casos favoráveis.

Nota-se que para o cenário otimista o período de payback passa para dois anos e analisando os demais indicadores apresentados, observa-se que quanto maior a quantidade beneficiada e embalada, mais rápido ocorre o retorno financeiro.

Comparando todos os cenários, conforme se aumenta a quantidade de matéria-prima a ser beneficiada, os indicadores econômicos acompanham este aumento, da mesma forma que se a quantidade é reduzida, os valores dos indicadores também diminuem.

\section{Conclusão}

O projeto mostrou-se viável tecnicamente e passível de execução mesmo em nível de pequena propriedade rural, pois a quantidade de maçãs produzidas na mesma apresentou-se suficiente para o beneficiamento durante todo o ano, desde que possua câmaras frigoríficas para o armazenamento refrigerado das frutas, devido à alta perecibilidade destas.

Em qualquer cenário econômico estudado o projeto é viável e atrativo, até na pior condição climática, pois ainda tem-se um payback pequeno (4 anos) e um alto valor da VPL.

A TIR em todos os cenários é maior que a TMA, indicando que mais vale investir no projeto, a deixar o dinheiro em alguma aplicação financeira.

\footnotetext{
Abstract

The case study refers to a farm with 35 ha of orchards, 50\% of the area planted with apple trees in the 50\% group Gala and Fuji. The aim of this work was to study the technical and economic feasibility of the installation of a wastewater processing and packaging apple "in nature, predicting an increase from the fourth year, totaling 3,000 t.ano-1. For the design of the equipment was calculated mass balance. Moreover, planning was conducted on the number of employees required and their functions. To market analysis was conducted a survey, by digital means, for people of
} 
different cities of Rio Grande do Sul, of different ages, social classes and education. As for the economic study was carried out a strategic review to determine the business unit. The investments were planned to be performed in zero-three year planning horizon of 10 years. Once obtained all the values, we elaborated cash flow. They were constructed to simulate different scenarios economical situations of risk based on events for any agricultural this case, the climatic factors. We conclude that in any economic study design is feasible and attractive, even in the worst weather conditions, they still have to be a little payback (4 years) and a high value of NPV. The IRR in all scenarios is greater than the TMA, indicating that it is better to invest in the project, leaving the money in some financial investment.

Key-words: malus domestica; packing house; agroindustrial process.

\section{Referências}

ABREU, Marcelo Faoro de; GUASSELLI, Idair Gaudêncio Girardi; FAORO, Roberta Rodrigues. Um estudo sobre a atuação em múltiplos elos da cadeia produtiva: o caso da maçã no Sul do Brasil. In: SIMPÓSIO DE EXCELÊNCIA EM GESTÃo E TECNOLOGIA, 6. Anais... Resende, 2009.

AGAPOMI; EMATER. Produção de maçãs no RS Safra 2010/2011. Vacaria, 2012. Disponível em: <http://www.agapomi.com.br/arquivos/Safra.pdf>. Acesso em: 25 nov. 2012.

ANSOFF, H.I. Estratégia empresarial. São Paulo: MsGraw Hill, 1979.

BRASIL. Ministério da Agricultura, Pecuária e Abastecimento. Instrução normativa no 5 de 09/02/2006 da Lei no 9972. Disponível em: <http://sistemasweb.agricultura.gov.br/sislegis/ action/detalhaAto.do?method=consultarLegislacaoFederal> . Acesso em: 20 nov. 2012.

BRUNI, Adriano Leal; FAMÁ, Rubens; SIQUEIRA, José de Oliveira. Análise do risco na avaliação de projetos de investimento: uma aplicação do método de Monte Carlo. Caderno de Pesquisas em Administração. São Paulo, v. 1. p. 62-75. 1998.

BUARQUE, Cristovam. Avaliação econômica de projetos: uma apresentação didática. 6 ed. Rio de Janeiro: Campus, 1991. 266p.

CELLI, Marcos Giovani; COELHO, Alexandre Rodrigo; WOSIACKI, Gilvan; GARCIA-CRUZ, Crispin Humberto. Patulina: incidência e controle em derivados de maçã. Semina: Ciências Agrárias. Londrina, v. 30, n. 1. p. $135-162$. 2009.

CONTADOR, C.R. Indicadores para seleção de projetos. In: CONTADOR, C. (Ed.) Avaliação social de projetos. 2.ed. São Paulo: Atlas, 1988.

CHITARRA, Maria Isabel Fernandes; CHITARRA, Adimilson Bosco. Pós- colheita de frutas e hortaliças: fisiologia e manuseio. Lavras: UFLA, 2005. 785 p.

CONAB. Sistema Prohort. Disponível em: <http://www3.ceasa.gov.br/prohortweb/>. Acesso em: 14 nov. 2012.

EPAGRI. A cultura da macieira. Florianópolis, 2002. 743 p.

FAO. Produção mundial de maçãs, 2010. Disponível em: <faostat.fao.org/site/339/default.aspx>. Acesso em: 01 dez. 2012.

FIGUEIREDO, Adelson Martins; SANTOS, Pedro Antônio dos; SANTOLIN, Roberto; REIS, Brício dos Santos. Integração na criação de frangos de corte na microrregião de Viçosa - MG: viabilidade econômica e análise de risco. Revista de Economia e Sociologia Rural. Brasília, v.44. p.713-730. 2006.

FIORAVANÇO, João Caetano; GIRARDI, César Luís; CZERMAINSKI, Ana Beatriz Costa; SILVA, Gildo Almeida da; NACHTIGALL, Gilmar Ribeiro; OLIVEIRA, Paulo Ricardo Dias de. Cultura da macieira no Rio Grande do Sul: análise situacional e descrição varietal. Bento Gonçalves: Embrapa, 2010. 60p.

GIRARDI, César Luís. Boas práticas agrícolas e pós-colheita na produção integrada de maçãs. Bento Gonçalves. EMBRAPA/CNPUV, 2002. 12 p. (Embrapa Uva e Vinho, Circular Técnica, n.37). 
GIRARDI, César Luís; MAIA, Leonardo Raseira; ROMBALDI, César Valmor. Manejo da fruta na central de embalagem. In: GIRARDI, C. L. Frutas do Brasil, Embrapa, Brasília, 2004. 67p.

IBGE. Instituto Brasileiro de Geografia e Estatística. Sistema automático de recuperação de dados: produção 2011. Disponível em: <http://www.sidra.ibge.gov.br/bda/prevsaf/ default.asp?t=1\&z=t\&o=26\&u2=1\&u3=1\&u4=1\&u1=34> . Acesso em: 16 nov. 2012.

MONTEIRO NETO, Carlos de Barros. Marcas próprias em supermercados: uma oportunidade para a criação de vantagem competitiva. Caderno de pesquisas em administração. São Paulo, v. 8. p. 55-64. 2001.

NORONHA, J.F. Projetos agropecuários: administração financeira, orçamento e viabilidade econômica. 2. ed. São Paulo: Atlas, 1987. 269p.

PEREIRA, Laércio Barbosa; SIMIONI, Flávio José; CARIO, Silvio Antônio Ferraz. Evolução da produção de maçã em Santa Catarina: novas estratégias em busca da competitividade. In: Encontro de Economia Catarinense, 1. 2007, Joinvile. Anais eletrônicos... Joinvile: UNESC, 2007. Disponível em: <http://www.apec.unesc.net/I\%20EEC/sessoes_tematicas/Rural_agricola/artigo2.PDF>. Acesso em: 23 nov. 2012.

PERES, Afonso Aurélio de Carvalho; SOUZA, Paulo Marcelo de; MALDONADO, Hernan; SILVA, José Fernando Coelho da; SOARES, Cezar da Silva; BARROS, Suzana Correa Wagner; HADDADE, Ismail Ramalho. Análise econômica de sistemas de produção a pasto para bovinos no município de Campos de Goytacazes-RJ. Revista Brasileira de Zootecnia. Viçosa, v. 33, p. 1557-1563, 2004.

PERES, Afonso Aurélio de Carvalho; VÁSQUEZ, Hernán Maldonado; SOUZA, Paulo Marcelo de; SILVA, José Francisco Coelho da; VILLELA, Omar Vieira; SANTOS, Fernando Cesar dos. Análise financeira e de sensibilidade de sistemas de produção de leite em pastagem. Revista Brasileira de Zootecnia, v. 38, n. 10, p. 2072-2078, 2009.

PETRI, José Luiz; LEITE, Gabriel Berenhauser. Macieira. Revista Brasileira de Fruticultura. Jaboticabal, v.30, n.4. 2008.

ROMBALDI, Cesar Valmor; TIBOLA; Casiane Salete; FACHINELLO, José Carlos; SILVA, Jorge Adolfo. Percepção de consumidores do Rio Grande do Sul em relação a quesitos de qualidade em frutas. Revista Brasileira de Fruticultura (online), v. 29, n. 3, p. 681-684, 2007. http://dx.doi.org/10.1590/S0100-29452007000300049

SAMPAIO FILHO, Antonio Carlos de Souza. Taxa interna de retorno modificada: proposta de implementação automatizada para cálculo em projetos não-periódicos, não necessariamente convencionais. Dissertação. Mestrado em Administração. IBMEC, Rio de Janeiro. 2008.

SANHUEZA, Rosa Maria Valdebenito. Recomendações para o controle das podridões pós-colheita de maçãs. Bento Gonçalves. EMBRAPA/CNPUV, 1996. 4 p. (Embrapa Uva e Vinho, Comunicado Técnico, n. 21).

Submetido em 27 mai. 2013; Aceito para publicação em 14 abr. 2014. 